\title{
Some Observations on the use of Penicillinase in Sterility Tests for Penicillin
}

\author{
By M. PILE, D. D. STEWART AND A. F. B. STANDFAST \\ The Bacteriological Laboratory, The British Drug Houses Ltd., London
}

\begin{abstract}
SUMMARY: Penicillinase preparations strong enough to destroy all the penicillin in $1 \mathrm{hr}$. or less at room temperature should be used in carrying out sterility tests on solid penicillin. Otherwise, penicillin-sensitive contaminants may be killed by the penicillin before it is destroyed and samples containing them will be sterile by the test. A convenient unit of penicillinase is the quantity which will destroy 100 units of penicillin in $1 \mathrm{ml}$. in $1 \mathrm{hr}$. at room temperature $\left(24^{\circ}\right)$.
\end{abstract}

The usual sterility tests when applied to penicillin can show the presence only of penicillin-resistant organisms, any penicillin-sensitive organisms present in the dry penicillin powder being killed when the penicillin is dissolved. For obvious reasons it is not possible to dilute the penicillin to a concentration at which it is no longer active, for the quantities of broth necessary would be unmanageable.

In order to overcome this difficulty, Harper (1943) suggested the use of penicillinase in sterility tests, and Proom (1945) described the preparation of penicillinase from a paracolon bacillus in a strength suitable for sterility tests of high-potency penicillin. Lawrence (1943) reported that 'clarase' was a satisfactory agent for destroying penicillin in sterility tests, though later work has shown that this was probably due to a penicillinase in the 'clarase'.

The usefulness of penicillinase in sterility tests depends on its ability to destroy the penicillin before the penicillin has killed any of the penicillinsensitive organisms which might be present. Although in the literature there are references to the fact that 'small numbers' of organisms were not affected by the penicillin in penicillin-penicillinase mixtures, we were not satisfied with the evidence, particularly as most workers use undetermined numbers of the test organisms to test the inactivation of the penicillin, assuming, if on incubation the test organism grew out, that the penicillin had been destroyed.

Some of our preliminary experiments indicated that though such inocula might multiply in these mixtures of penicillin and inactivating agent, some of the bacteria might have been killed before the penicillin was destroyed.

The experiments described below were designed to demonstrate the degree to which this killing occurred in the conditions of routine sterility tests. They show that, in order to destroy all penicillin activity before any contaminants are killed, very large quantities of penicillinase are necessary. 


\section{Material and methods}

Penicillin. Samples of commercial penicillin calcium salt (about 500 units/mg.) were used. Penicillin was assayed by the routine plate method used in this laboratory.

Penicillinase. Batches of penicillinase were prepared from a paracolon bacillus by the method of Proom (1945) and from $B$. subtilis by the methods of Coulthard (personal communication), Smith (1945) and those devised in this laboratory.

Viable counts. All viable counts were made in roll tubes containing $1 \mathrm{ml}$. of double strength agar, to accommodate the inoculum of $1 \mathrm{ml}$. per roll tube necessary to demonstrate small numbers of organisms. Six replicates of each count were made.

All roll tubes were incubated at $37^{\circ}$ and counted after 1 day, and again after 7-14 days, in case the penicillin had produced an abnormally long lag phase in some of the bacteria. In no experiment, however, was this the case. For example, three tubes having 39, 42 and 50 colonies after 1 day were counted as 39,39 and 49 after 10 days' incubation.

\section{The assay of penicillin-penicillinase mixtures}

Residual penicillin in penicillin-penicillinase mixtures can be titrated by the cup-plate method. The continued action of the penicillinase during the incubation of the test plate is offset by the fact that penicillin diffuses through the agar at a much greater rate than penicillinase. For example, when lots of 100 units of penicillin were mixed with $1,2,3$ and 5 arbitrary units (see p. 250) of penicillinase, the mixture immediately diluted 1 in 100 and placed in the cups, the differences between the mean diameters of the inhibition rings (average of six replicates) produced by the control penicillin and the various penicillin-penicillinase mixtures were within the experimental error of the plate assay. The penicillin, having diffused away from the penicillinase through the agar, was not destroyed during incubation of the cup-plate.

This method of demonstrating penicillin activity has given us more consistent results than did the titration of penicillin after extraction from the mixtures. Five hundred units of penicillin in $5 \mathrm{ml}$. were plunged into ice-cold water, adjusted to $\mathrm{pH} \mathrm{3.0} \mathrm{and} \mathrm{shaken} \mathrm{for} 15 \mathrm{~min}$. with an equal volume of chloroform. The chloroform after separation was shaken with an equal volume of sodium bicarbonate solution. The process was repeated on a sample of the penicillin with 500 units $/ \mathrm{ml}$. of penicillinase. All the samples were diluted so as to contain approximately $1 \mathrm{unit} / \mathrm{ml}$. and assayed by the plate method. The ring diameters were:

Original penicillin

Extracted penicillin

Extracted penicillin-penicillinase
$21.5 \mathrm{~mm} . \equiv 100$ units $/ \mathrm{ml}$.

$18 \cdot 6 \mathrm{~mm} . \equiv 86$ units $/ \mathrm{ml}$.

$17 \cdot 0 \mathrm{~mm} . \equiv 79$ units $/ \mathrm{ml}$. 
It is probable that the $86-79=7$ units lost in the penicillinase mixture were destroyed while the solutions were being adjusted to $\mathrm{pH} 3.0$ and perhaps during the shaking with chloroform. All similar experiments showed this loss.

When penicillin is incorporated in the agar in a test plate and penicillinase put in the cups, rings of staphylococcal growth are obtained where the penicillinase has diffused into the agar. For plates containing 1 unit of penicillin $/ \mathrm{ml}$. of agar, solutions containing 2000 arbitrary units of penicillinase $/ \mathrm{ml}$. are needed to get rings of a diameter (about $18 \mathrm{~mm}$.) comparable to that given by 1 unit of penicillin (about $21 \mathrm{~mm}$. diam.) in the ordinary cup-plate titration.

Table 1. The killing of staphylococci in penicillin-penicillinase mixtures at room temperature

\begin{tabular}{|c|c|c|c|c|c|c|}
\hline \multirow{2}{*}{ Composition of mixtures } & \multicolumn{6}{|c|}{ Samples taken at (hr.) } \\
\hline & 0 & 1 & 2 & 4 & 6 & 24 \\
\hline Penicillin Penicillinase & \multicolumn{6}{|c|}{ Mean viable counts and residual penicillin $/ \mathrm{ml}$. } \\
\hline o & 78 & 68 & 70 & 57 & 55 & $\infty$ \\
\hline $5400 \quad 0$ & $\int 78$ & $\mathbf{0}$ & $\mathbf{0}$ & $\mathbf{0}$ & $\mathbf{0}$ & $\mathbf{0}$ \\
\hline Residual penicillin & $\{$. & + & + & + & + & + \\
\hline $0 \quad 4$ & 78 & $\mathbf{7 4}$ & 72 & 69 & 74 & $\infty$ \\
\hline $5400 \quad 4$ & $\{78$ & 14. & 17 & 30 & 37 & $\infty$ \\
\hline Residual penicillin & $\{$. & + & + & \pm & 0 & $\mathbf{0}$ \\
\hline $\begin{array}{ll}\mathbf{0} & \mathbf{2}\end{array}$ & 78 & 78 & 63 & 81 & 74 & $\infty$ \\
\hline 5400 & $\int 78$ & 2 & 1 & 7 & 8 & 24 \\
\hline Residual penicillin & $\{$. & + & + & + & $\mathbf{0}$ & 0 \\
\hline $\begin{array}{ll}0 & 1\end{array}$ & 78 & 72 & 71 & 65 & 74 & $\infty$ \\
\hline $5400 \quad 1$ & $\int 78$ & 0 & $\mathbf{0}$ & 0 & $\mathbf{0}$ & 0 \\
\hline Residual penicillin & $\{\cdot$ & + & + & + & + & $\mathbf{0}$ \\
\hline $\begin{array}{ll}0 & 0.5\end{array}$ & 78 & 74 & 74 & 62 & 68 & $\infty$ \\
\hline $5400 \quad 0.5$ & $\int 78$ & 0 & $\mathbf{0}$ & $\mathbf{0}$ & $\mathbf{0}$ & $\mathbf{3}$ \\
\hline Residual penicillin & $\{$. & + & + & + & + & 0 \\
\hline \multicolumn{7}{|c|}{$\begin{array}{l}\infty=\text { more than } 1 \text { million organisms } / \mathrm{ml} . \\
\text { Penicillin assay. } \begin{aligned}+ & =\text { more than } 0.5 \mathrm{unit} / \mathrm{ml} \\
& \pm=\text { about } 0.1 \mathrm{unit} / \mathrm{ml} . \\
0 & =\text { no demonstrable penicillin. }\end{aligned}\end{array}$} \\
\hline
\end{tabular}

Solutions of penicillinase of such strength that $1 \mathrm{ml}$. will destroy 100 units of penicillin do not give measurable rings on agar plates containing 1 unit of penicillin $/ \mathrm{ml}$.

It is therefore possible to titrate the residual penicillin in mixtures by the plate method.

\section{Rate of destruction of penicillin by penicillinase}

At room temperature. In the first series of experiments, a penicillinase was used of such a strength that $0.5 \mathrm{ml}$. would destroy 6000 units of penicillin in $24 \mathrm{hr}$. Quantities from $0.5 \mathrm{ml}$. to $4.0 \mathrm{ml}$. were added to 5400 units of penicillin in broth. Staph. aureus (Oxford, Heatley strain) was added to give a final concentration of $80 \mathrm{viable}$ cocci $/ \mathrm{ml}$. The final volume of broth in each tube was $66 \mathrm{ml}$. and therefore the final concentration of penicillin was $82 \mathrm{units} / \mathrm{ml}$. The 
tubes were stood at room temperature and at the times stated sampled without further dilution for viable counts and penicillin assays. The results of a typical experiment are shown in Table 1.

It will be seen that even with a large concentration of penicillinase, the penicillin is not destroyed quickly enough to allow all the organisms to survive. The tube containing $4 \mathrm{ml}$. of penicillinase shows a drop from about 78 to 37 cocci $/ \mathrm{ml}$. in $6 \mathrm{hr}$., by which time there was no penicillin left to be carried over into the roll tubes; in the tube with $2 \mathrm{ml}$. of penicillinase there were only 8 cocci

\section{Table 2. The killing of staphylococci in penicillin-penicillinase mixtures at $37^{\circ}$}

The figures show increased rates of reaction in penicillin-penicillinase mixtures at $37^{\circ}$ as compared with room temperature (see Table 1).

\begin{tabular}{|c|c|c|c|c|c|c|}
\hline \multirow{2}{*}{ Composition of mixtures } & \multicolumn{6}{|c|}{ Samples taken at (hr.) } \\
\hline & 0 & & $\boldsymbol{2}$ & 4 & & 24 \\
\hline Penicillin Penicillinase & \multicolumn{6}{|c|}{ Mean viable count and residual penicillin $/ \mathrm{ml}$. } \\
\hline 0 & 48 & 46 & 40 & 300 & $\infty$ & $\infty$ \\
\hline 5400 & 48 & 31 & 36 & 33 & 511 & $\infty$ \\
\hline Residual penicillin & . & + & \pm & $\mathbf{0}$ & $\mathbf{0}$ & 0 \\
\hline $5400 \quad 2$ & 48 & 4 & 8 & 29 & 129 & $\infty$ \\
\hline $\begin{array}{l}5400 \quad 2 \\
\text { Residual penicillin }\end{array}$ & . & + & + & 0 & 0 & $\mathbf{0}$ \\
\hline $54,00 \quad 1$ & 48 & $\mathbf{0}$ & 0 & 0 & $\mathbf{2}$ & $\infty$ \\
\hline $\begin{array}{l}5400 \quad 1 \\
\text { Residual penicillin }\end{array}$ & . & + & + & \pm & $\mathbf{0}$ & $\mathbf{0}$ \\
\hline $\begin{array}{ll}5400 & 0.5\end{array}$ & 48 & 0 & 0 & 0 & 0 & $\infty$ \\
\hline Residual penicillin & . & + & + & + & + & $\mathbf{0}$ \\
\hline $5400 \quad 0$ & 48 & 0 & 0 & 0 & $\mathbf{0}$ & $\mathbf{0}$ \\
\hline Residual penicillin & . & + & + & + & + & + \\
\hline
\end{tabular}

Symbols as in Table 1 .

left after the destruction of the penicillin by the penicillinase. It should be noted that penicillinase alone showed no bacterial or bacteriostatic activity in the concentrations used.

At $37^{\circ}$. Three experiments, one of which is set out in detail in Table 2, were carried out at $37^{\circ}$ to see if the penicillin-penicillinase reaction would be accelerated and the exposure of the cocci to the penicillin thereby shortened.

With $4 \mathrm{ml}$. of penicillinase, which destroyed all the penicillin in less than $4 \mathrm{hr}$., the viable count had fallen from about $48 \mathrm{cocci} / \mathrm{ml}$. at $0 \mathrm{hr}$. to $33 \mathrm{cocci} / \mathrm{ml}$., compared with the control tube at $4 \mathrm{hr}$. with 300 cocci $/ \mathrm{ml}$. With $1 \mathrm{ml}$. of penicillinase, which destroyed all the penicillin in $6 \mathrm{hr}$., the viable count had been reduced to $2 \mathrm{cocci} / \mathrm{ml}$. though in $24 \mathrm{hr}$. these had grown out to more than 1 million. This experiment illustrates a fallacy of penicillin-penicillinase experiments in which viable counts are not made, for at $\mathbf{2 4} \mathbf{h r}$. the bacterial density in this tube was equal to that in the control, although a large number of cocci had been killed by the penicillin before it was destroyed by the penicillinase. 
Experiments with staphylococci, streptococci and B. subtilis

The experiments showing that staphylococci may be killed by penicillin in the presence of large quantities of penicillinase were repeated with other organisms (Table 3).

Table 3. The killing of staphylococci, streptococci and B. subtilis in penicillin-penicillinase mixtures at room temperature

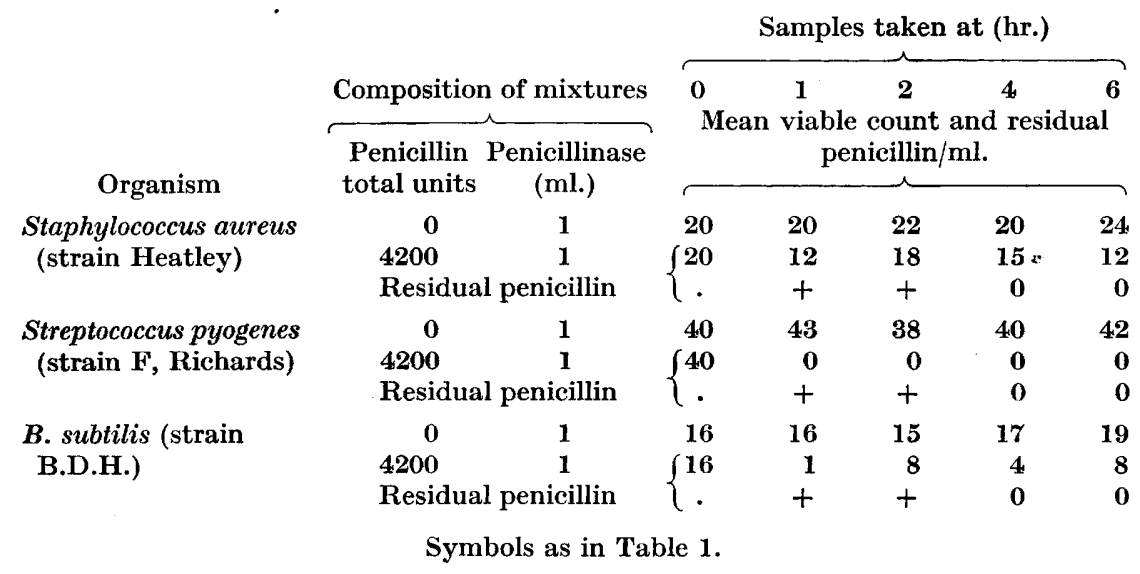

Here again, the destruction of penicillin by penicillinase was not sufficiently rapid (Table 3). In $4 \mathrm{hr}$., by which time all the penicillin had been destroyed, the staphylococci had been diminished from 20 to 15, the streptococci had been killed and the $B$. subtilis counts reduced from 16 to 4 organisms $/ \mathrm{ml}$. The last figure is too low to be counted accurately by the roll tube method, but the regularity of the count, $2,3,3,3,5,7$, average 4 colonies/roll tube, gives an indication of the behaviour of $B$. subtilis.

\section{The use of large quantities of penicillinase in sterility tests}

From the foregoing experiments it is clear that penicillinase in much larger quantities than has been customary must be used for a satisfactory sterility test. A series of tests were set up with penicillinase of a strength such that $2 \mathrm{ml}$. would destroy 6000 units of penicillin in $1 \mathrm{hr}$. at room temperature. Residual penicillin was accurately titrated from 50 units $/ \mathrm{ml}$. downwards. These tests gave similar results, and one test is set out in full (Table 4).

With 2 and $4 \mathrm{ml}$. of penicillinase, which destroyed all the penicillin in $1 \mathrm{hr}$., there was no significant killing of staphylococci, but with $1 \mathrm{ml}$., which decreased the penicillin from 92 units $/ \mathrm{ml}$. to $0 \cdot 8 \mathrm{unit} / \mathrm{ml}$. in $2 \mathrm{hr}$. and destroyed it all in $4 \mathrm{hr}$, the viable count was decreased to $25 \mathrm{cocci} / \mathrm{ml}$. in $4 \mathrm{hr}$. With $0.5 \mathrm{ml}$. of penicillinase which destroyed all the penicillin in $6 \mathrm{hr}$., the viable count was only 8 .

Repeated tests with penicillinase at this strength, i.e. 4 or $8 \mathrm{ml}$. of a strength 
such that $2 \mathrm{ml}$. would destroy all the penicillin present in $1 \mathrm{hr}$. or less, showed that this is a satisfactory strength to ensure that none of the organisms present is killed by the penicillin.

\section{DISCUSSION}

These experiments show that if penicillinase is employed it must be used in a concentration sufficient to destroy the penicillin before it has killed any contaminating organisms, if falsely negative results are to be avoided. The importance of this fact cannot be stressed too highly when very small numbers of penicillin-sensitive contaminating organisms are to be detected.

Table 4. The rapid inactivation of penicillin by large quantities of a suitable penicillinase at room temperature

Test organism: Staphylococcus aureus.

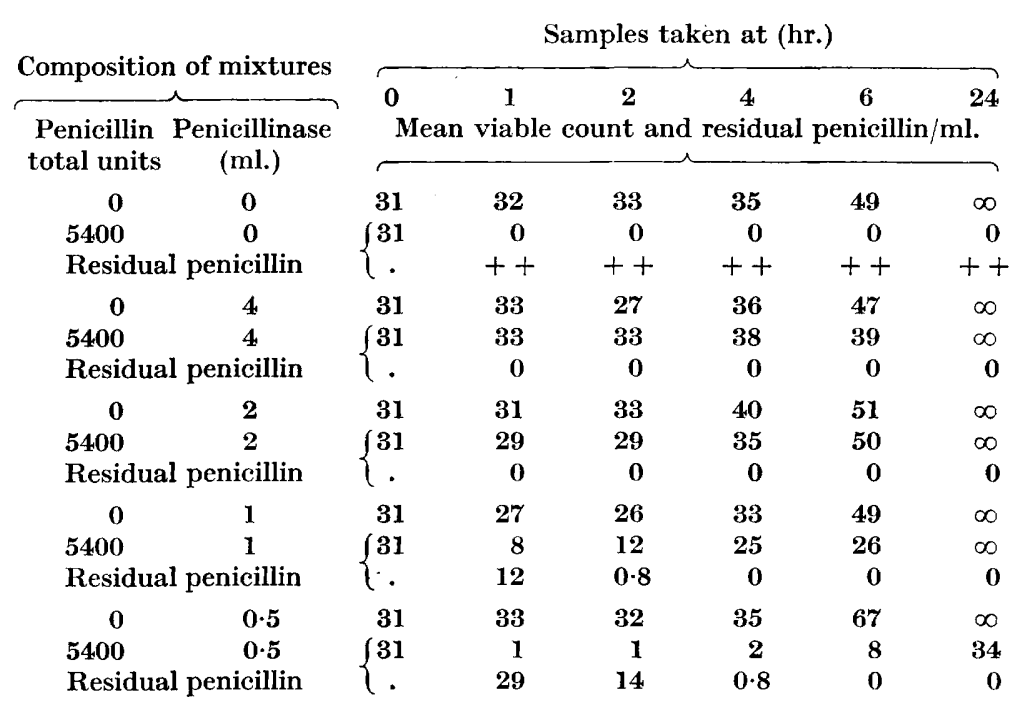

Penicillin assay. $++=$ more than 50 units $/ \mathrm{ml}$. Other symbols as in Table 1.

It is customary to assay penicillinase in terms of the quantity of the preparation under test which will destroy 100 units of penicillin. However, the time taken for the destruction and the temperature are important, and the potency of the penicillinase should be reported as the quantity which will destroy 100 units of penicillin in $1 \mathrm{ml}$. in a given period and at a given temperature. From the practical viewpoint of sterility testing, we suggest that the time of the reaction should not exceed $1 \mathrm{hr}$. and that room temperature is better than $37^{\circ}$. At $37^{\circ}$, though the destruction of the penicillin is more rapid and the amount required rather less, the action of penicillin on bacteria is also more rapid and there is a greater danger of contaminants being killed. 
A potent and rapidly acting penicillinase is necessary for satisfactory sterility tests, and we suggest that a convenient unit of penicillinase activity is the quantity of a preparation that will destroy 100 units of penicillin in $1 \mathrm{ml}$. in $1 \mathrm{hr}$. at room temperature. A penicillinase like that used in the experiments described in Table 4, if used in excess, would probably protect the most penicillin-sensitive contaminant.

We wish to thank the Directors of the British Drug Houses Ltd. for permission to publish this paper.

\section{REFERENCES}

HARPER, G. J. (1943). Inhibition of penicillin in routine culture media. Lancet, ii, 569.

Lawrence, C. A. (1943). Sterility tests for penicillin. Science, 98, 413.

Proom, H. (1945). Some observations on penicillinase. Brit. J. exp. Path. $26,98$.

Smith, W. \& Smrth, M. M. (1945). Production of sterile and stable penicillinase. Lancet, i, 809. 